$10-2011$

\title{
Prevalence and Prognostic Role of Triple-Negative Breast Cancer by Race: A Surveillance Study
}

\section{Helen Swede}

University of Connecticut School of Medicine and Dentistry

David I. Gregorio

University of Connecticut School of Medicine and Dentistry

Susan H. Tannenbaum

University of Connecticut School of Medicine and Dentistry

Jessica A. Brockmeyer

University of Connecticut School of Medicine and Dentistry

Lori L. Wilson

University of Connecticut School of Medicine and Dentistry

See next page for additional authors

Follow this and additional works at: https://opencommons.uconn.edu/uchcres_articles Part of the Life Sciences Commons, and the Medicine and Health Sciences Commons

\section{Recommended Citation}

Swede, Helen; Gregorio, David I.; Tannenbaum, Susan H.; Brockmeyer, Jessica A.; Wilson, Lori L.; Pensa, Mellisa A.; Stevens, Richard G.; and Runowicz, Carolyn D., "Prevalence and Prognostic Role of Triple-Negative Breast Cancer by Race: A Surveillance Study" (2011). UCHC Articles - Research. 268.

https://opencommons.uconn.edu/uchcres_articles/268 
Authors

Helen Swede, David I. Gregorio, Susan H. Tannenbaum, Jessica A. Brockmeyer, Lori L. Wilson, Mellisa A. Pensa, Richard G. Stevens, and Carolyn D. Runowicz 


\title{
Prevalence and Prognostic Role of Triple-Negative Breast Cancer by Race: A Surveillance Study
}

\author{
Helen Swede ${ }^{1}$, David I. Gregorio ${ }^{1}$, Susan H. Tannenbaum ${ }^{2}$, Jessica A. Brockmeyer ${ }^{1}$, \\ Christine Ambrosone ${ }^{3}$, Lori L. Wilson ${ }^{2}$, Mellisa A. Pensa ${ }^{1}$, Lou Gonsalves ${ }^{4}$, Richard G. \\ Stevens $^{1}$, and Carolyn D. Runowicz ${ }^{2}$ \\ ${ }^{1}$ Department of Community Medicine \& Health Care, University of Connecticut School of \\ Medicine, Farmington, CT \\ ${ }^{2}$ Neag Cancer Center, University of Connecticut Health Center, Farmington, CT \\ ${ }^{3}$ Department of Cancer Prevention and Control, Roswell Park Cancer Institute, Buffalo, NY \\ ${ }^{4}$ Connecticut Tumor Registry, Department of Public Health, Hartford CT
}

\begin{abstract}
A possible explanation for the relatively poor survival from breast cancer among blacks is the much higher rate of the adverse Triple-Negative sub-type. In a study of 1372 patients, blacks had twice the risk of death compared to whites among those with advanced cancer whether or not tumors were Triple-Negative. More research is still warranted to determine why blacks with advanced, but not local, breast cancer have a consistently higher rate of death.
\end{abstract}

Introduction-Emerging research suggests a substantially greater prevalence of the adverse triple-negative (TN) subtype (human epidermal growth factor receptor [HER $] 2^{-}$, estrogen receptor $[\mathrm{ER}]^{-}$, and progesterone receptor $\left.[\mathrm{PR}]\right)^{-}$) among black patients with breast cancer. No reports however have been generated from a statewide cancer registry.

Patients and Methods-The study consisted of all black patients $(\mathrm{N}=643)$ and a random sample of white patients $(n=719)$ diagnosed with primary invasive breast cancer $(2000-2003)$ listed in the National Cancer Institute-Surveillance Epidemiology and End Results (NCI-SEER) Connecticut Tumor Registry (CTR). HER2 status was obtained from pathology reports submitted to the registry. Remaining data were obtained from the registry database.

Results-TN tumors were more prevalent in black compared with white patients (30.8\% vs. $11.2 \%$, respectively; $P<.001$.) There was a 2-fold greater frequency of $\mathrm{ER}^{-}$and $\mathrm{PR}^{-}$phenotypes among black patients, but HER2 status did not differ by race. Patients with lobular cancer were less likely to have TN breast cancer compared with patients with ductal tumors (odds ratio [OR] $=$ 0.23 ; $95 \%$ confidence interval $[\mathrm{CI}], 0.10-0.58$ ). Among patients with regional disease, black

(C) 2011 Elsevier Inc. All rights reserved.

Address correspondence to: Helen Swede, PhD, Department of Community Medicine \& Health Care, University of Connecticut School of Medicine, 263, Farmington Avenue, Farmington, CT 06030, Fax: 860-679-5464; hswede@uchc.edu.

Disclosure

All authors report that they have no relevant relationships to disclose. 
patients exhibited increased risk of death (relative risk $[\mathrm{RR}]=2.71 ; 95 \% \mathrm{CI}, 1.48-4.97$ )

independent of TN status. No survival disparity was found among patients with local disease.

Discussion-These registry-based data corroborate reports that $\mathrm{TN}$ breast cancer varies substantially by race and histologic subtype. A survival disparity among patients with advanced disease, but not local disease, casts some doubt on TN status as an explanation for differences.

Conclusion-More research is warranted to understand why black patients with advanced breast cancer may be at increased risk for death whether or not their tumors express the TN phenotype.

\section{Keywords}

Biologic markers; Breast neoplasms; Health status disparities; HER2; Race/ethnicity; Triple negative breast cancer

\section{Introduction}

Despite consistently lower incidence rates for breast cancer, black patients have substantially higher mortality rates compared with whites. ${ }^{1-4}$ Disparate outcomes are likely due to an array of socioeconomic, behavioral, and clinic factors. ${ }^{1,5-7}$ Emerging evidence from hierarchical genome-wide classification studies also suggest that differential expression profiles may explain, in part, the mortality disparity. Four recently identified expression clusters, referred to as intrinsic subtypes, are thought to represent biologically distinct disease entities. ${ }^{8,9}$ Of these, the basal-like subtype tends to confer a significantly worse prognosis ${ }^{10,11}$ and has been found in an approximately 3 -fold greater proportion among black patients compared with white patients. ${ }^{12}$ This subtype is characterized by low expression of the estrogen receptor (ER), progesterone receptor (PR), and human epidermal growth factor receptor 2 (HER2); high expression of proliferative genes, such as MK167, certain basal cytokeratins (eg, CK5, CK6, CK17), and EGFR1; frequent mutations in p53 and other genes; and dysfunction of the BRCAl gene. ${ }^{11,13}$ The other gene clusters are HER2-enriched, characterized by high expression of HER2 yet little or no expression of hormone receptors; luminal A, characterized mostly by expression of ER and associated genes; and luminal $B$, which is also mostly ER-expressing but is distinguished from luminal A by a relatively high-proliferation gene signature (eg, $K i-67)$ and a subset positive for HER2 expression. ${ }^{8,9,14,15}$

Because genomic expression profiling is not yet standard in the clinic setting, an immunohistochemical (IHC) designation known as triple-negative (TN) breast cancer (ER ${ }^{-}$, $\mathrm{PR}^{-}$, and HER2 ${ }^{-}$) has emerged as a proxy categorization for the basal-like subtype. ${ }^{10,13}$ Although TN breast cancer does not share many of the molecular features of the basal-like subtype, a number of studies have reported comparable associations with worse survival. ${ }^{10}$ Results from a nested case study of 476 patients from a population-based cohort derived from the Atlanta metropolitan area reported that TN breast cancers were far more prevalent among younger women, particularly younger black women. ${ }^{16}$ Hospital-based case series from the Boston area ${ }^{17}$ and Marshfield Clinic ${ }^{18}$ in Wisconsin also reported an almost tripling of TN among black patients compared with white patients. 
To investigate the distributions and outcomes of TN breast cancer by race in a populationbased study, we used data from the Connecticut Tumor Registry (CTR), a statewide registry in the Surveillance, Epidemiology, and End Results (SEER) program of the National Cancer Institute (NCI). We performed a multiyear record review of 1362 patients with breast cancer, including all newly diagnosed breast cancers among black women and a comparably sized random sample of white women diagnosed during 2000-2003. To our knowledge, there have been no estimates of the prevalence and prognostic importance of the TN subtype derived from a statewide surveillance source.

\section{Patients and Methods}

\section{Population}

Data were obtained from the CTR, a participant site in the NCI-SEER program, on patients diagnosed with primary invasive female breast cancers (ICD-O-3 codes C500-C509) between January 1, 2000 and December 31, 2003. Of the full population of black patients with breast cancer during the study period, 96.5\% (643/666) were included in analyses. Reasons for exclusions $(\mathrm{n}=23)$ were duplicate records of the same case or discrepant information about racial status. A comparably sized random sample of white women (n =755) was selected from among 10,473 eligible cases in the CTR database. Matching on demographic variables was not performed in order to determine the actual prevalence of the variables under study. Of the 755 white women, 36 were excluded for reasons similar to those noted earlier, with a resultant total of 719 (95.2\%) records reviewed. Access to patient information was approved by the Institutional Review Boards of the University of Connecticut Health Center and the State of Connecticut Department of Public Health.

\section{Surveillance Epidemiology and End Results Database}

Information obtained from the CTR database included the following: ER, PR, age at diagnosis, SEER summary stage at diagnosis (local, regional, and distant), ${ }^{15}$ ICD-O-3 histologic subtypes, ${ }^{19}$ tumor grade (I, II, III/IV), number of positive axillary lymph nodes, and tumor size $(\mathrm{cm})$. We combined all regional SEER summary substages into a single category. Histologic codes from World Health Organization ICD-O 3rd edition were used to create 5 subtypes: purely ductal (ICD-O codes 8500-8509, 8201); purely lobular (ICD-O code 8520); mixed ductal and lobular (ICD-O codes 8522-8524); medullary (ICD-O codes 8510-8513) and other (eg, Paget disease, ICD-O code 8541; phyllodes, ICD-O code 9020), and un-classified (ICD-O codes 8000; 8010-8141; 8211, 8230, 8401, 8480, 8490; 8530-8980). Ductal and lobular were separated based on evidence that HER2 is typically not expressed in lobular breast cancer. ${ }^{20,21}$ Procedures at the CTR for obtaining vital status and ICD cause of death have been reported in detail. ${ }^{22}$ Briefly, routine follow-up is obtained directly from reporting hospitals and through record linkages with state vital statistics, state motor vehicle records, centers for Medicare and Medicaid services, and the Social Security Administration. Cause of death is routinely obtained from computerized state death record files or the National Death Index Plus database. Vital status was selected as the clinical endpoint because recurrence or metastasis detected subsequent to the initial diagnosis is not routinely collected by SEER registries. 


\section{HER2 Status}

Summary pathology reports submitted to the CTR were reviewed to ascertain HER2 test result and summary descriptors (ie, positive or negative). Summary descriptors in the absence of a specific test value were accepted as HER2 status. If specific IHC test values were not accompanied by a summary descriptor, we classified positivity status in accordance with the prevailing scoring system during the study period (2000-2003) in which scores of $2+$ or $3+$ indicated HER 2 overexpression, and 0 or $1+$ were considered HER2- ${ }^{23}$ Protocol to conduct confirmatory fluorescence in situ hybridization (FISH) testing for 2+IHC scores became standardized soon after the timeframe of our study. ${ }^{24}$ Of the 166 patients listed as having HER $2^{+}$tumors, 19 (11.4\%) were considered unconfirmed 2+scores. Of the 37 cases listed descriptively (only) as borderline in the pathology report, 15 were subsequently tested by FISH, and of these, 2 were reported to be amplified. The remaining 13/15 were listed as HER 2- in our analyses, as were the 22/37 borderline cases not subsequently tested by FISH. FISH results of $\geq 2$ were classified as positive consistent with a recent survey of laboratory practices conducted by the College of American Pathologists. ${ }^{25}$ Records indicating findings for both FISH and IHC tests $(n=42)$ were classified according to FISH results. Reports in which the test result conflicted with the overall pathology report decision (eg, 3+ but deemed negative) were excluded from analyses $(n=22)$. As described in our earlier report, of patients whose pathology reports indicated that a HER2 test had been ordered, test results were available for $96 \%$ of black and $98 \%$ of white patients. ${ }^{26}$ The vast majority of the assays were IHC analyses, and less than $10 \%$ were IHC analyses followed by FISH or FISH alone.

\section{Triple Subtypes}

We used surrogate groupings based on IHC values for HER2, ER, and PR (Table 1) in accordance with groupings in recent studies. ${ }^{14,17,18,27}$ The summary pathology reports did not contain information on cytokeratins, HER $1^{+}$, and other molecular components of the genomic-based intrinsic subtypes.

\section{Statistical Analyses}

Descriptive analyses comparing clinicopathologic characteristics between black and white patients were evaluated using a $\chi^{2}$ test for the categorical variables: triple subtypes (Table 1), tumor grade (I/II, III/IV), histologic type, condensed SEER summary stage (local, regional, distant), HER2 status, ER status, PR status, tumor size category $(<2 \mathrm{~cm}, 2 \mathrm{~cm}$ to $<$ $5 \mathrm{~cm},>5 \mathrm{~cm}$ ), axillary lymph node status (positive, negative), and vital status (alive, dead from any cause); $t$ tests were used for independent samples to assess mean differences between black and white patients in regard to the following continuous variables: follow-up time among patients still alive at the end of the study period, age, tumor size, and number of positive axillary lymph nodes.

Logistic regression was performed to calculate odds ratios (ORs) and corresponding 95\% confidence intervals (CIs) for binary outcomes of TN vs. non-TN breast cancers for black compared with white patients with breast cancer. Two multivariate models were constructed using established prognostic factors in breast cancer. Model 1 included patient age at diagnosis, tumor size $(\mathrm{cm})$, tumor grade, and number of positive lymph nodes. Model 2 
added histologic subtypes. Multivariate models were forced (ie, established prognostic factors) and Hosmer-Lemeshow goodness of fit (GOF) tests were nonsignificant (model 1: GOF $\chi^{2}=3.89 ; P=.87 ;$ model 2 : GOF $\chi^{2}=9.63 ; P=.29$ ), indicating that model predictions did not differ significantly from observations.

Differences in survival time between the dichotomous study groups (TN, non-TN) were estimated using Cox multivariate proportional hazards analysis and illustrated with KaplanMeier curves. We stratified analyses a priori by SEER summary stage of disease (local, regional, distant) because of the mixed evidence of prognostic value of HER2 status in nodenegative patients. ${ }^{28}$ Two forced models were constructed using the same variables included in the logistic regression. Survival time among patients who died was defined as months from date of diagnosis to date of death. Patients alive at the end of the study were rightcensored, with a survival time endpoint of date of last follow-up. Outcome event was any cause of death as listed in the CTR database. Survival analyses excluded patients with distant disease because of the very poor 5-year survival rate ${ }^{4}$ and those who survived less than 1 month after diagnosis to exclude possible surgical failures $(n=1)$. All statistical analyses were carried out using PASW Statistics version 17.0 (formerly SPSS Statistics; SPSS, Chicago, IL) and were assessed with 2-sided $P$ values.

\section{Results}

As shown in Table 2, when compared with whites, black patients with breast cancer were diagnosed at a younger age (mean of 57.6 vs. 62.5 years, respectively; $P<.001$ ), were more likely to be $<50$ years (33.1\% vs. $21.1 \%$, respectively; $P<.001$ ), and presented with higher grade $(P<.001)$ and larger tumors (mean of $2.32 \mathrm{~cm}$ vs. $2.00 \mathrm{~cm} ; P<.001)$. White patients had nearly twice the prevalence of lobular tumors $(9.3 \%$ vs. $5.3 \%$; omnibus $P=.001)$ and a markedly lower prevalence of medullary tumors $(0.4 \%$ vs. $3.3 \%$; omnibus $P=.001)$ compared with black patients. Compared with whites, black patients presented with somewhat larger tumors on average ( 2.00 vs. $2.32 \mathrm{~cm}$, respectively; $P<.001)$.

\section{Distribution of HER2/ER/PR Subtypes Varied by Race}

Compared with white patients, black patients with breast cancer had nearly 3 times the prevalence of TN breast cancer, and almost double the rate of the $\mathrm{ER}^{-} / \mathrm{PR}^{-} / \mathrm{HER} 2^{+}$subtype (30.8\% vs. $11.2 \%, 9.2 \%$ vs. $4.8 \%$, respectively; omnibus $P<.001$ ) (Table 3 ). This distribution did not change appreciably when counting $2+$ IHC values as HER2 ${ }^{-}(31.7 \%$ vs. $11.0 \%, 7.9 \%$ vs. $4.7 \%$, respectively; omnibus $P<.001$; data not shown). Tumors from black patients were far more likely than those from whites to test negative for estrogen $(39.7 \%$ vs. $17.6 \%$, respectively; $P<.001)$ and progesterone ( $47.3 \%$ vs. $29.2 \%$, respectively; $P<.001)$ receptors, yet exhibited a comparable rate of HER2 positivity to that of whites (20.5\% vs. $17.1 \%$, respectively; $P=0.19)$. HER2 positivity rates for black and white patients did not change appreciably when counting $2+$ IHC scores as negative for overexpression $(16.0 \%$ vs. $16.1 \%$, respectively; $P=0.94$; data not shown). TN frequency was somewhat lower in patients with local disease (18.3\%) compared with those with regional and distant stages at presentation $(25.1 \%, 27.8 \%$, respectively; $P=.049$, data not shown). 
As seen in Table 4, black women were almost 3 times more likely than white women to be diagnosed with TN breast cancer (multivariate $\mathrm{OR}=2.93 ; 95 \% \mathrm{CI}, 1.88-4.57$ ) when controlling for age at diagnosis, tumor size, tumor grade, and number of positive nodes in model 1, which persisted when histologic subtype was added as a covariate (multivariate OR $=2.95 ; 95 \%$ CI, 1.87-4.66) in model 2 . Patients with purely lobular cancers however were significantly less likely to present with TN breast cancer compared with the study referent group of those with purely ductal cancers (multivariate $\mathrm{OR}=0.25 ; 95 \% \mathrm{CI}, 0.07-0.89$ ). Likewise patients with mixed lobular and ductal disease were significantly less likely to have $\mathrm{TN}$ tumors (multivariate $\mathrm{OR}=0.23$; 95\% CI, 0.10-0.58). Conversely patients with medullary tumors were 3.37 times more likely (95\% CI, 0.94-12.10) to present with TN breast cancer, but this finding did not reach statistical significance $(P<.06)$.

Given the variation in TN status by race and histologic subtype (Table 4), we examined if differences held for each of the underlying 3 biomarkers (HER2, ER, and PR). Descriptive analyses in Table 5 show that the frequency of HER2 positivity did not vary by race in tumors with ductal or lobular histologic features, although lobular-based tumors tended to display lower HER2 expression. ER and PR phenotypes however varied substantially by both race and histologic features. For those with purely ductal tumors, eg, twice as many black patients were diagnosed with the more adverse $\mathrm{ER}^{-}$phenotype compared with whites (44.7\% vs. $20.3 \%$, respectively; $P<.001$ ). For lobular-based breast cancer, the difference in ER negativity was nearly 3 -fold for blacks compared with whites (15.0\% vs. $5.3 \%$, respectively; $P=.01$ ). Similar patterns were observed for PR status, but the difference between black and white patients was not statistically significant. Overall, a greater proportion of ductal tumors, compared with those of pure or composite lobular histologic characteristics, expressed the TN phenotype ( $23.0 \%$ vs. $6.4 \%$, respectively; $P<.001$; data not shown) or were HER2 ${ }^{+}(21.2 \%$ vs. $13.8 \%$, respectively; $P<.05$; data not shown). In contrast, tumors of purely ductal histologic features were more likely to be $\mathrm{ER}^{-}$compared with lobular-based tumors (68.2\% vs. $90.5 \%$, respectively; $P<.001$.) More than $90.0 \%$ of tumors with a lobular component did not express the TN phenotype, which did not differ by race $(P=0.95)$. There were too few patients $(\mathrm{n}=156)$ with other histologic subtypes (eg, medullary) to have reliable counts in the stratified race, subtype, and histologic type crosstabulations.

Black breast cancer patients with local disease had a $40 \%$ increased risk of death (Table 6A) compared with white patients in the age-adjusted analysis (RR, 1.41; 95\% CI, 1.03-1.93), but risk estimates were reduced to null in the multivariate models. When examining regional disease (Table 6B) however black patients with breast cancer exhibited a more than doubled risk of death compared with whites in age-adjusted analyses, which was maintained in the 2 multivariate models. Univariate Kaplan-Meier curves (Figure 1) illustrate survival patterns according to race and stage. Among patients with TN tumors, there were no differences in survival between blacks and whites for patients who presented with local stage disease (Figure 1A). However among patients with regional stage diagnoses (Figure 1B), blacks had worse survival than whites (Mantel-Cox log-rank test, $P=.005$ ). A similar variation in survival was observed for patients with non-TN breast cancer (Figure 1C, D). Black patients with TN tumors and regional disease had the shortest survival time. 
To assess possible selection bias because of the large number of patients excluded resulting from missing data on TN status ( $\mathrm{n}=467)$, which was mostly because of unknown HER2 status, we compared several characteristics of included vs. excluded patients (data not shown). Included patients were younger on average (mean of 59.0 years vs. 61.8 years, respectively; $P=.001$ ) and were somewhat more likely to be black ( $49.4 \%$ of included vs. $43.7 \%$ of excluded; $P=.05$ ). The percent of patients still living at the end of the follow-up period did not vary between the 2 sets of patients $(P=.71)$ nor did the distribution of histologic subtypes $(P=.46)$. To further assess possible selection bias related to overrepresentation of younger patients in our study, we stratified TN prevalence to explore if this phenotype might vary by menopausal status using the surrogate measure of age (data not shown). We found that for patients $\$ 50$ years, $35.7 \%$ of black patients presented with TN tumors compared with only $11.3 \%$ of white patients $(P=.001)$. Similarly for those $>50$ years of age, the proportion of TN tumors among black patients was reduced 2-fold (26.4\% vs. $11.1 \%$, respectively; $P<.001$ ). Notably TN prevalence did not vary by age among white patients.

\section{Discussion}

In this analysis from a statewide cancer registry, we found a 2- to 3-fold difference in the prevalence of TN breast cancer among blacks compared with whites, in keeping with recent hospital-based and population-based clinical studies. ${ }^{16-18,29,30} \mathrm{We}$ found that the rate of TN tumors remained at about $11 \%$ for white patients both older and younger than 50 years, but varied by age among black patients (35\% vs. $24 \%$, respectively.) Our findings also are similar to previous reports that tumors from black patients with breast cancer tend to have significantly reduced ER or PR expression, ${ }^{31,32}$ whereas HER2 status does not appear to vary by race. ${ }^{7,33,34}$ Our findings suggest that divergent histologic distribution by race may underlie the disparity in TN status. Although the medullary subtype is relatively rare, we found that blacks had an almost 9-fold greater rate than that of white patients (3.3\% vs. $0.40 \%$ ), which is consistent with several earlier reports. ${ }^{32,35,36}$ Further, as in our analysis it has been reported that medullary tumors have a relatively higher rate of the TN phenotype. ${ }^{10}$ We speculate that the higher prevalence of TN tumors among black patients might explain in part survival disparity because several studies have reported that this subtype is relatively more aggressive because of its high nuclear grade. ${ }^{37}$ Others however have reported that medullary cancer confers a favorable prognosis despite sharing features with breast cancer subtypes that have a poor prognosis. ${ }^{38} \mathrm{We}$ did not have sufficient numbers of patients with medullary cancer to perform a thorough prognostic analysis, however. Future investigations of disparities, particularly of TN breast cancer, would benefit from oversampling of medullary and other rare types so that race and age patterns can be explored more fully.

Recent investigations have shed some light on the possible origins of TN tumors. A recent study reported that patients with TN tumors were more likely to be obese or overweight compared with patients with tumors exhibiting the $\mathrm{ER}^{+} / \mathrm{PR}^{+} / \mathrm{HER} 2^{+}$phenotype. ${ }^{27}$ Authors also found that $\mathrm{ER}^{-}$and $\mathrm{PR}^{-}$tumors were associated with younger age at birth of first child. However Stead et al found TN status to be independent of age and weight. ${ }^{17} \mathrm{Kwan}$ et al observed that the association between obesity/overweight and TN breast cancer was seen among premenopausal but not postmenopausal women. ${ }^{29}$ In the Carolina Breast Cancer 
Study, increased parity raised the risk of basal-like breast cancer, ${ }^{37}$ which may be attenuated by relatively longer duration of breastfeeding as observed in 2 recent studies. ${ }^{29,38} \mathrm{~A}$ recent analysis by Huo et al in indigenous Nigeria and Senegal suggests that both behavioral and genetic background influence breast cancer subtype prevalence. ${ }^{39}$ Investigators reported a $27 \%$ prevalence of the basal-like subtype and a $17 \%$ prevalence of HER $2^{+}$breast cancers, which are consistent with our study and other analyses cited earlier in the African diaspora in the United States. Variation in subtype prevalence within indigenous populations implies etiologic heterogeneity, whereas similarity in prevalence across different geographic locations suggests a degree of genetic predisposition. Troester and Swift-Scanlan suggest that to better clarify risk factors for TN breast cancer, attention should be given to the age and racial compositions of study populations, ${ }^{40}$ to which we would like to add that histologic subtypes also may be informative.

Our multivariate findings of an increased risk of death among patients with TN tumors is consistent with previous reports, ${ }^{16}$ including survival studies based on the basal-like classification. ${ }^{12}$ Conversely our study, along with that of Carey et al in the Carolina Breast Study ${ }^{12}$ and of Lund et al's study in the Atlanta metropolitan area, ${ }^{16}$ casts some doubt that the substantial differential TN frequency explains survival disparity. We observed that disparities in survival were present only among patients with regional disease irrespective of TN status, which suggests that other influences may be at play within an otherwise homogeneous high-risk group. Lund et al found, eg, that disparities in treatment underlay survival differences in their large study. ${ }^{41}$ It also is possible that because IHC-based TN status is an imperfect surrogate for the microarray-derived basal-like subtype, other molecular factors (eg, BRCA1, basal cytokeratins, p53) might better distinguish black and white patients with advanced tumors. Although there is sizeable discordance between TN and basal-like subtype, ${ }^{13}$ evaluating the prognostic utility of TN continues to be of importance because microarray assays are not yet standard in routine practice resulting from high costs and time intensity. Further there is no targeted therapy for TN tumors by definition of their negativity, which otherwise would allow use of, eg, trastuzumab for HER $2^{+}$disease or chemoantagonists for hormone receptor-expressing tumors. ${ }^{10}$ Hence clarifying risk estimates for TN subgroups (eg, regional disease, lobular histologic type) may be of value for patient surveillance planning.

A secondary aim of our investigation was to evaluate the research utility of summary hospital pathology reports to obtain HER2 status for studies of NCI-SEER registry databases. NCI included HER2 as a reportable item in the SEER program starting with diagnosis year 2010. ${ }^{42}$ Until a sufficient number of years have transpired to conduct outcome studies however, researchers still may wish to obtain HER2 data from before 2010 . Our previous analysis of patterns of HER2 testing in the current set of patients ${ }^{26}$ indicated that approximately two thirds of them were tested for the biomarker. Lack of HER2 status in the report was the primary cause of missing TN status in our current study, but this gap is expected to be alleviated in the coming years now that HER2 status is a SEER reportable item. Despite missing information, our finding of a lack of significant difference in HER2 positivity between black and white patients is corroborated by several earlier reports. ${ }^{1,7,12,33,34,43}$ HER2 positivity in our study (IHC 2+ scores deemed either positive or 
negative) falls within the range of recent reports estimating prevalence to be $12 \%$ to $25 \%$ of sampled tumors, ${ }^{12,43-46}$ which is a narrowing from initial estimates that ranged up to $40 \%$.

It is likely that early studies overestimated prevalence because these investigations tended to be composed of high-risk cohorts or proportionally more patients with regional or metastatic disease. ${ }^{23}$ Designation of $2+$ scores as HER $2^{+}$might have introduced some error into our study because we did not have information on FISH confirmation for most cases. We speculate however that only a fraction of those cases subsequently would have been changed to $\mathrm{TN}$ because the great majority of tumors were $\mathrm{ER}^{+}$and/or $\mathrm{PR}^{+}$.

Information in pathology reports at a central registry may be a relatively bias-free source of HER2 status data because of nearly complete registration of all patients in the population and the fact that HER2 status is based on surgical tissue used for diagnostic purposes and is not dependent on tissue availability in residual archives, as is the case in conventional investigations. Lack of tissue for research can be a source of substantial selection bias. ${ }^{21}$ Studies using research archives or residual hospital biobanks have reported that tumors from patients for whom tissue was available tended to be significantly larger than those for whom tissue was no longer available. ${ }^{12,21,28}$ Overrepresentation of larger tumors may result in a bias toward the null in survival analyses; a single tumor marker or even a comprehensive molecular profile might not stand out as an independent factor in the context of advanced anatomic burden and concomitant genetic changes as tumors progress through the metastatic cascade. ${ }^{28}$

\section{Conclusion}

Our findings benefit from 4 years of data derived from a well-established, population-based, statewide cancer registry recognized for high quality and complete data. ${ }^{47}$ Still our results should be interpreted with some caution. The large proportion of missing data on HER2 status raises the prospect of bias due to an unmeasured confounder. Our prevalence and survival results, however, are consistent with earlier evidence, which offers the first supportive evidence of the general accuracy of HER2 data in a SEER registry. Lack of information on treatment is another limitation in our study. Given evidence of reported disparities in both receipt of treatment and prognostic factors in breast cancer, ${ }^{41}$ future TN studies should examine patterns of care, particularly for agents with known resistance or enhanced sensitivity to HER2 ${ }^{+}$tumors. Additionally, insurance coverage, socioeconomic status, patient decision making, and presence of comorbidities (eg, diabetes, heart disease) also may influence treatment use or effectiveness. Understanding treatment-related dynamics may illuminate why, in the community setting, black patients with advanced breast cancer disease appear to be at increased risk for death whether or not their tumors expressed the TN phenotype. Emerging research has focused on the roughly 3 -fold greater prevalence of the adverse TN phenotype in tumors of black patients as a possible explanation for survival disparity. However our stratified survival analyses cast some doubt on that hypothesis. Our findings may be applied to the future practice of cancer medicine by contributing to improved prognostic assessment of patients with breast cancer, particularly for black patients who have a substantially higher mortality rate despite a lower incidence of breast cancer. 


\section{Acknowledgments}

This study was funded in part by the Holger Hansen Graduate Student Research Fellowship, awarded by the Master of Public Health program at the University of Connecticut Health Center, and the NCI SEER program contract (N01-PC-35133) at the Connecticut Tumor Registry in the Connecticut Department of Public Health (DPH). This study was approved by the DPH Human Investigations Committee. Certain data used in this publication were obtained from DPH. The authors assume full responsibility for analyses and interpretation of these data.

\section{References}

1. Elledge RM, Clark GM, Chamness GC, et al. Tumor biologic factors and breast cancer prognosis among white, hispanic, and black women in the United States. J Natl Cancer Inst. 1994; 86:705-12. [PubMed: 7908990]

2. Newman LA, Griffith KA, Jatoi I, et al. Meta-analysis of survival in African American and white American patients with breast cancer: ethnicity compared with socioeconomic status. J Clin Oncol. 2006; 24:1342-9. [PubMed: 16549828]

3. Blackman DJ, Masi CM. Racial and ethnic disparities in breast cancer mortality: are we doing enough to address the root causes? J Clin Oncol. 2006; 24:2170-8. [PubMed: 16682736]

4. [Accessed May 8, 2011.] Surveillance Epidemiology and End Results: Cancer statistics review, 1975-2006. Available at http://seer.cancer.gov/csr/1975_2006/

5. Clegg LX, Reichman ME, Miller BA, et al. Impact of socioeconomic status on cancer incidence and stage at diagnosis: selected findings from the surveillance, epidemiology, and end results: national longitudinal mortality study. Cancer Causes Control. 2009; 20:417-35. [PubMed: 19002764]

6. Li CI, Malone KE, Daling JR. Differences in breast cancer stage, treatment, and survival by race and ethnicity. Arch Intern Med. 2003; 163:49-56. [PubMed: 12523916]

7. Jones BA, Kasl SV, Howe CL, et al. African-American/white differences in breast carcinoma: P53 alterations and other tumor characteristics. Cancer. 2004; 101:1293-301. [PubMed: 15368321]

8. Perou CM, Sorlie T, Eisen MB, et al. Molecular portraits of human breast tumours. Nature. 2000; 406:747-52. [PubMed: 10963602]

9. Sorlie T. Molecular portraits of breast cancer: Tumour subtypes as distinct disease entities. Eur J Cancer. 2004; 40:2667-75. [PubMed: 15571950]

10. Rakha EA, Ellis IO. Triple-negative/basal-like breast cancer: review. Pathology. 2009; 41:40-7. [PubMed: 19089739]

11. Sotiriou C, Pusztai L. Gene-expression signatures in breast cancer. N Engl J Med. 2009; 360:790800. [PubMed: 19228622]

12. Carey LA, Perou CM, Livasy CA, et al. Race, breast cancer subtypes, and survival in the Carolina Breast Cancer Study. JAMA. 2006; 295:2492-502. [PubMed: 16757721]

13. Schneider BP, Winer EP, Foulkes WD, et al. Triple-negative breast cancer: risk factors to potential targets. Clin Cancer Res. 2008; 14:8010-8. [PubMed: 19088017]

14. Cheang MC, Chia SK, Voduc D, et al. Ki67 index, HER2 status, and prognosis of patients with luminal B breast cancer. J Natl Cancer Inst. 2009; 101:736-50. [PubMed: 19436038]

15. Greene, FL.; Page, DL.; Fleming, ID., et al. AJCC Cancer Staging Handbook. 6. Chicago, IL: American Joint Committee on Cancer; 2002. p. 469

16. Lund MJ, Trivers KF, Porter PL, et al. Race and triple negative threats to breast cancer survival: a population-based study in Atlanta, GA. Breast Cancer Res Treat. 2009; 113:357-70. [PubMed: 18324472]

17. Stead LA, Lash TL, Sobieraj JE, et al. Triple-negative breast cancers are increased in black women regardless of age or body mass index. Breast Cancer Res. 2009; 11:R18. [PubMed: 19320967]

18. Onitilo AA, Engel JM, Greenlee RT, et al. Breast cancer subtypes based on ER/PR and Her2 expression: comparison of clinicopathologic features and survival. Clin Med Res. 2009; 7:4-13. [PubMed: 19574486]

19. Fritz, A.; Jack, A.; Parkin, DM., et al. International Classification of Diseases for Oncology. 3. Geneva, Switzerland: World Health Organization; 2000. 
20. Gusterson BA, Gelber RD, Goldhirsch A, et al. Prognostic importance of c-erbB-2 expression in breast cancer. International (Ludwig) Breast Cancer Study Group. J Clin Oncol. 1992; 10:1049_ 56. [PubMed: 1351538]

21. Donegan WL. Tumor-related prognostic factors for breast cancer. CA Cancer J Clin. 1997; 47:2851. [PubMed: 8996077]

22. Polednak AP. Comorbid diabetes mellitus and risk of death after diagnosis of colorectal cancer: a population-based study. Cancer Detect Prev. 2006; 30:466-72. [PubMed: 17069990]

23. Wolff AC, Hammond ME, Schwartz JN, et al. American Society of Clinical Oncology/College of American Pathologists guideline recommendations for human epidermal growth factor receptor 2 testing in breast cancer. J Clin Oncol. 2007; 25:118-45. [PubMed: 17159189]

24. Zarbo RJ, Hammond ME. Conference summary, strategic science symposium. her-2/neu testing of breast cancer patients in clinical practice. Arch Pathol Lab Med. 2003; 127:549-53. [PubMed: 12708896]

25. Persons DL, Tubbs RR, Cooley LD, et al. HER-2 fluorescence in situ hybridization: results from the survey program of the College of American Pathologists. Arch Pathol Lab Med. 2006; 130(3): 325-31. [PubMed: 16519559]

26. Pensa M, Swede H, Brockmeyer JA, et al. Patterns of HER2 testing in the management of primary breast cancer. Cancer Epidemiol. 2009; 33:113-7. [PubMed: 19679057]

27. Trivers KF, Lund MJ, Porter PL, et al. The epidemiology of triple-negative breast cancer, including race. Cancer Causes Control. 2009; 20:1071-82. [PubMed: 19343511]

28. Swede H, Moysich KB, Winston JS, et al. Variation of the prognostic significance of HER-2 expression in breast cancer according to tumor size. Breast J. 2003; 9:98-105. [PubMed: 12603382]

29. Kwan ML, Kushi LH, Weltzien E, et al. Epidemiology of breast cancer subtypes in two prospective cohort studies of breast cancer survivors. Breast Cancer Res. 2009; 11(3):R31. [PubMed: 19463150]

30. Lund MJ, Butler EN, Hair BY, et al. Age/race differences in HER2 testing and in incidence rates for breast cancer triple subtypes: A population-based study and first report. Cancer. 2010 Mar 24.

31. Morris GJ, Naidu S, Topham AK, et al. Differences in breast carcinoma characteristics in newly diagnosed African-American and Caucasian patients: a single-institution compilation compared with the National Cancer Institute's Surveillance, Epidemiology, and End Results database. Cancer. 2007; 110:876-84. [PubMed: 17620276]

32. Kovi J, Mohla S, Norris HJ, et al. Breast lesions in black women. Pathol Annu. 1989; 24(Pt 1): 199-218. [PubMed: 2654837]

33. Al-Abbadi MA, Washington TA, Saleh HA, et al. Differential expression of HER-2/NEU receptor of invasive mammary carcinoma between Caucasian and African American patients in the Detroit metropolitan area. Correlation with overall survival and other prognostic factors. Breast Cancer Res Treat. 2006; 97:3-8. [PubMed: 16432664]

34. Stark AT, Claud S, Kapke A, et al. Race modifies the association between breast carcinoma pathologic prognostic indicators and the positive status for HER-2/neu. Cancer. 2005; 104:218996. [PubMed: 16208704]

35. Anderson WF, Chu KC, Chang S, et al. Comparison of age-specific incidence rate patterns for different histopathologic types of breast carcinoma. Cancer Epidemiol Biomarkers Prev. 2004; 13:1128-35. [PubMed: 15247123]

36. Walker RA, Martin CV. The aged breast. J Pathol. 2007; 211:232-40. [PubMed: 17200937]

37. Middleton LP, Chen V, Perkins GH, et al. Histopathology of breast cancer among AfricanAmerican women. Cancer. 2003; 97(1 suppl):253-7. [PubMed: 12491489]

38. Marginean F, Rakha EA, Ho BC, et al. Histological features of medullary carcinoma and prognosis in triple-negative basal-like carcinomas of the breast. Mod Pathol. 2010; 23:1357-63. [PubMed: 20581807]

39. Huo D, Ikpatt F, Khramtsov A, et al. Population differences in breast cancer: survey in indigenous African women reveals over-representation of triple-negative breast cancer. J Clin Oncol. 2009; 27:4515-21. [PubMed: 19704069] 
40. Troester MA, Swift-Scanlan T. Challenges in studying the etiology of breast cancer subtypes. Breast Cancer Res. 2009; 11:104. [PubMed: 19635173]

41. Lund MJ, Brawley OP, Ward KC, et al. Parity and disparity in first course treatment of invasive breast cancer. Breast Cancer Res Treat. 2008; 109:545-57. [PubMed: 17659438]

42. Reichman ME, Altekruse S, Li CI, et al. Feasibility study for collection of HER2 data by National Cancer Institute (NCI) Surveillance, Epidemiology, and End Results (SEER) Program central cancer registries. Cancer Epidemiol Biomarkers Prev. 2010; 19(1):144-7. [PubMed: 20056633]

43. Wu Y, Khan H, Chillar R, et al. Prognostic value of plasma HER-2/neu in African American and Hispanic women with breast cancer. Int J Oncol. 1999; 14:1021-37. [PubMed: 10339653]

44. Pritchard KI, Shepherd LE, O'Malley FP, et al. HER2 and responsiveness of breast cancer to adjuvant chemotherapy. N Engl J Med. 2006; 354:2103-11. [PubMed: 16707747]

45. Owens MA, Horten BC, Da Silva MM. HER2 amplification ratios by fluorescence in situ hybridization and correlation with immunohistochemistry in a cohort of 6556 breast cancer tissues. Clin Breast Cancer. 2004; 5:63-9. [PubMed: 15140287]

46. Anderson WF, Luo S, Chatterjee N, et al. Human epidermal growth factor receptor-2 and estrogen receptor expression, a demonstration project using the residual tissue repository of the Surveillance, Epidemiology, and End Results (SEER) program. Breast Cancer Res Treat. 2009; 113:189-96. [PubMed: 18256926]

47. Glaser SL, Clarke CA, Gomez SL, et al. Cancer surveillance research: a vital subdiscipline of cancer epidemiology. Cancer Causes Control. 2005; 16:1009-19. [PubMed: 16184466] 


\section{Clinical Practice Points}

Despite consistently lower incidence rates for breast cancer, black patients tend to have substantially higher mortality rates compared to whites. Emerging research suggests that the greater prevalence of the adverse Triple-Negative subtype among black breast cancer patients might contribute to the disparity in outcome.

Among patients with regional disease, black patients exhibited reduced survival compared to whites while controlling for Triple-Negative status, age, tumor size, number of positive axillary lymph nodes, tumor grade, and histological subtype. In contrast, we found no evidence of disparity among patients with local stage disease.

Until reasons for survival disparity are better understood, black patients with regional disease may need heightened monitoring for recurrence even if their tumors do not exhibit the relatively aggressive $\mathrm{TN}$ phenotype. 


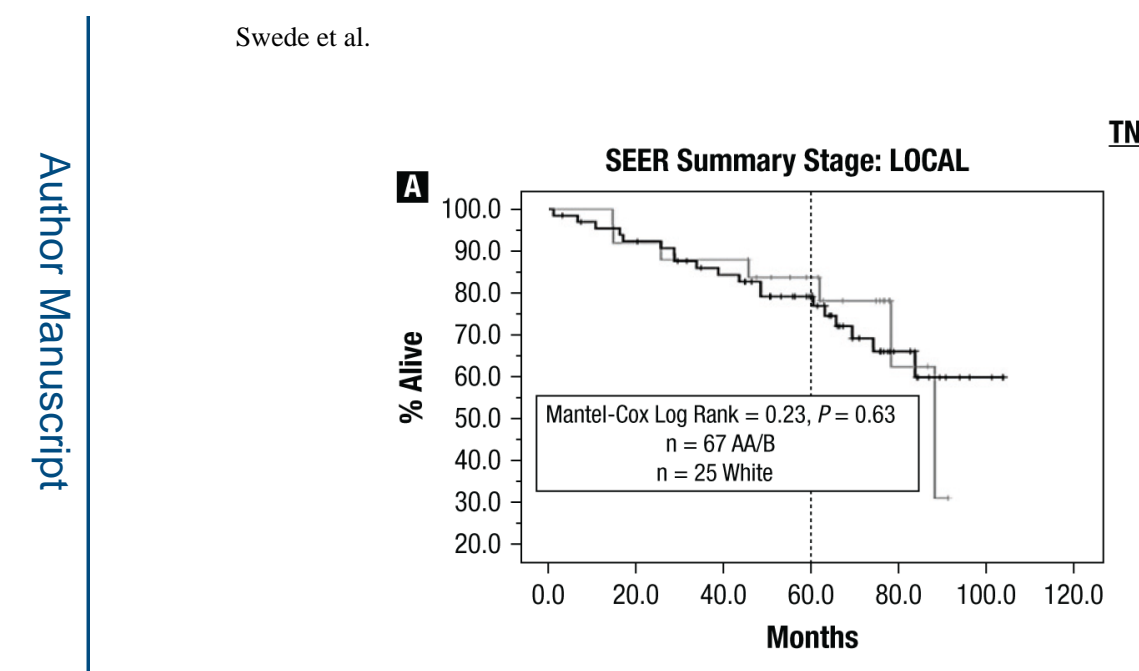

TN TUMORS
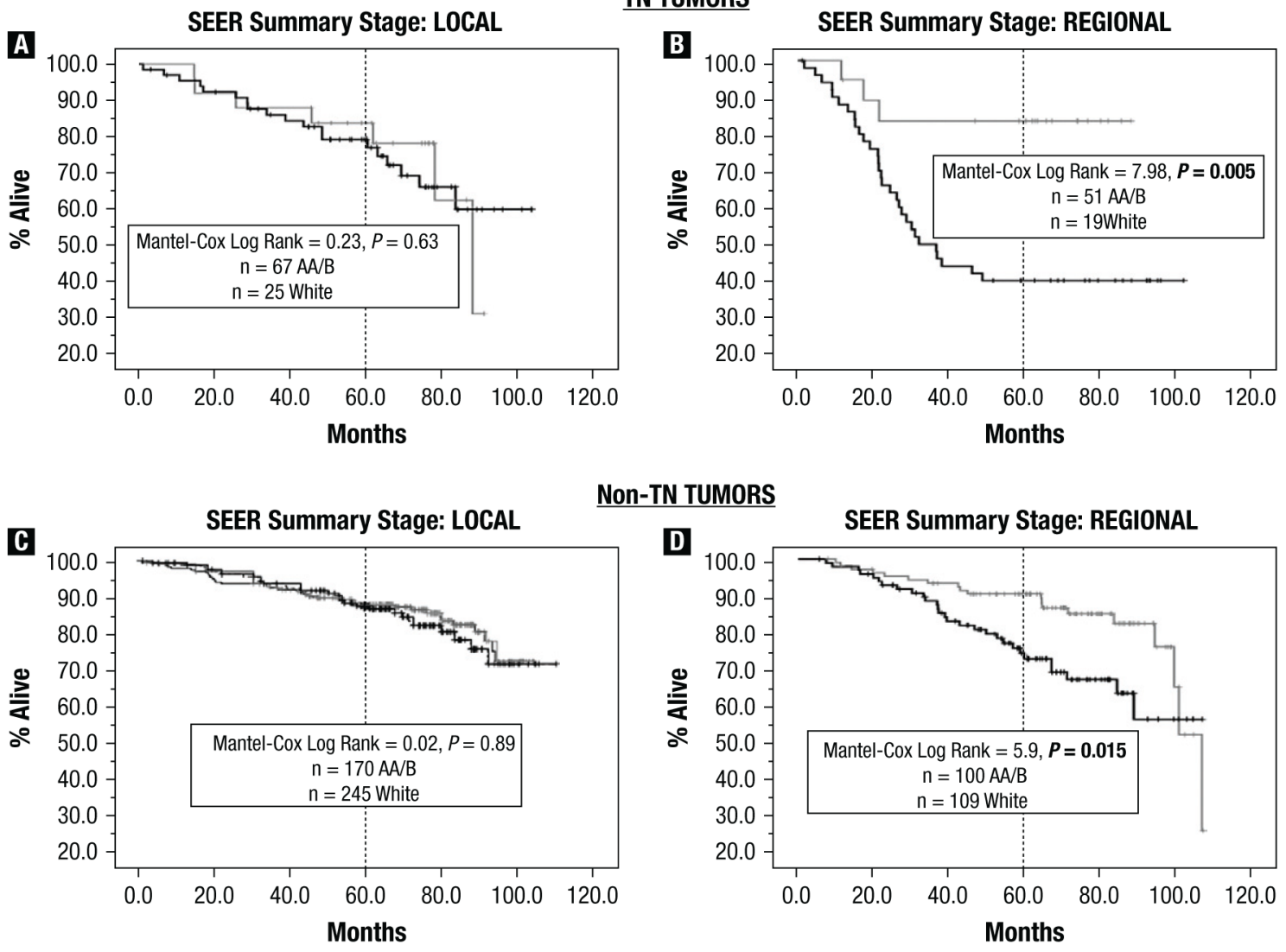

NON-TN TUMORS

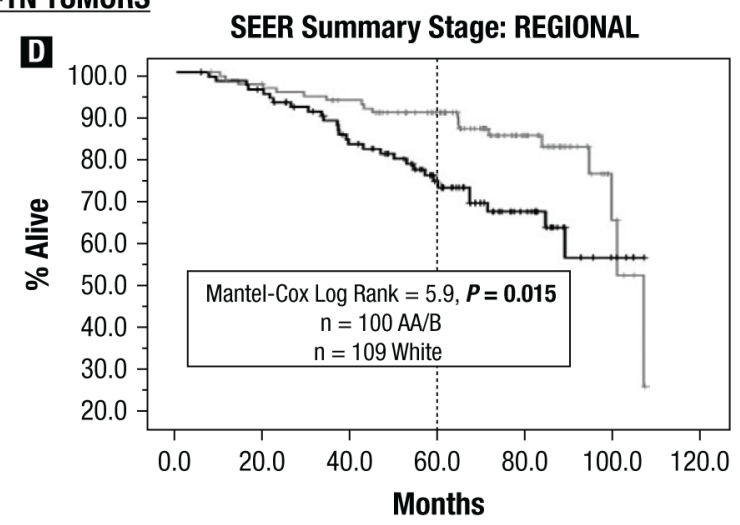

$\neg$ White $\curvearrowleft$ AA/B + White-censored + AA/B-censored

Figure 1.

Kaplan-Meier Survival Curves Depicting Overall Survival from Breast Cancer in Relation to Triple-Negative Tumor Status and SEER Summary Stage, NCI-SEER Connecticut Tumor Registry, 2000-2003 
Table 1

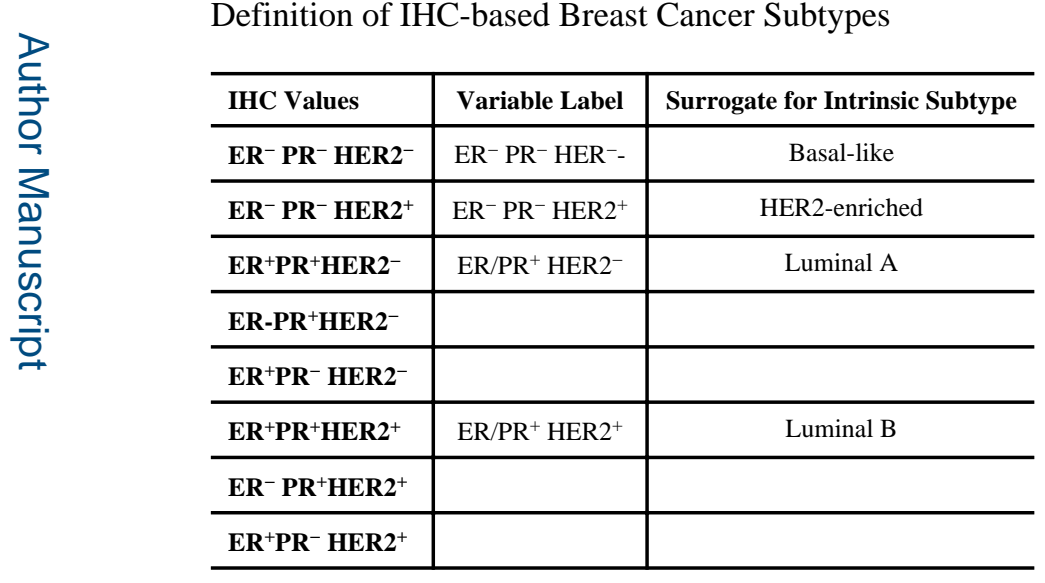

Abbreviations: ER = estrogen receptor; HER = human epidermal growth factor receptor; PR = progesterone receptor. 


\section{Table 2}

Clinicopathologic Characteristics of 1362 Breast Cancer Patients According to Race, NCI-SEER Connecticut Tumor Registry, 2000-2003

\begin{tabular}{|c|c|c|c|}
\hline & White $(n=719)$ & Black $(n=643)$ & $P$ Value $^{a, b}$ \\
\hline Alive n (\%) & $543(75.5 \%)$ & $457(71.1 \%)$ & .06 \\
\hline Median Follow-up Time Among Alive & 73.2 months & 68.1 months & $.03^{c}$ \\
\hline \multicolumn{4}{|l|}{ Age at Diagnosis (Years) } \\
\hline Mean (SD) & $62.5(14.8)$ & $57.6(14.1)$ & $<.001$ \\
\hline$<50$ & $152(21.1 \%)$ & $213(33.1 \%)$ & $<.001$ \\
\hline $50+$ & $567(78.9 \%)$ & $430(66.9 \%)$ & \\
\hline \multicolumn{4}{|l|}{ SEER Summary Stage } \\
\hline Local & $452(64.5 \%)$ & $379(60.7 \%)$ & .29 \\
\hline Regional & $213(30.4 \%)$ & $215(34.5 \%)$ & \\
\hline Distant & $36(5.1 \%)$ & $30(4.8 \%)$ & \\
\hline Unstaged/missing & 18 & 19 & \\
\hline \multicolumn{4}{|l|}{ Histologic Subtype } \\
\hline Ductal & $490(69.4 \%)$ & $434(67.6 \%)$ & .001 \\
\hline Lobular & $66(9.3 \%)$ & $34(5.3 \%)$ & \\
\hline Mixed ductal and lobular & $85(12.0 \%)$ & $84(13.1 \%)$ & \\
\hline Medullary & $3(0.4 \%)$ & $21(3.3 \%)$ & \\
\hline Other or unclassified & $62(8.8 \%)$ & $69(10.7 \%)$ & \\
\hline Unknown & 13 & 1 & \\
\hline \multicolumn{4}{|l|}{ Tumor Grade } \\
\hline I & $94(15.1 \%)$ & $57(9.9 \%)$ & .001 \\
\hline II & $262(42.0 \%)$ & $213(37.1 \%)$ & \\
\hline $\mathrm{III} / \mathrm{IV}$ & $268(42.9 \%)$ & $304(53.0 \%)$ & \\
\hline Unknown & 69 & 95 & \\
\hline \multicolumn{4}{|l|}{ Axillary Lymph Nodes } \\
\hline Mean no. positive (SD) & $1.20(2.9)$ & $1.36(3.2)$ & .39 \\
\hline Negative & $365(65.2 \%)$ & $312(60.3 \%)$ & .10 \\
\hline Positive & $195(34.8 \%)$ & $205(39.7 \%)$ & \\
\hline Not examined/unknown & 159 & 126 & \\
\hline \multicolumn{4}{|l|}{ Tumor Size } \\
\hline Mean mm (SD) & $2.00(1.6)$ & $2.32(1.8)$ & .001 \\
\hline$<2$ & $392(60.1 \%)$ & $289(50.3 \%)$ & .001 \\
\hline 2 to $<5$ & $216(33.1 \%)$ & $225(39.1 \%)$ & \\
\hline$>5$ & $44(6.7 \%)$ & $61(10.6 \%)$ & \\
\hline Unknown & 64 & 64 & \\
\hline Diffuse & 3 & 4 & \\
\hline
\end{tabular}


Abbreviation: SEER = Surveillance Epidemiology and End Results.

${ }^{a}$ Categorical variables evaluated with Pearson $\chi^{2}$ test of proportions.

${ }^{b}$ Continuous variables evaluated with $t$ test for independent samples except where noted.

${ }^{c}$ Evaluated using the Mann-Whitney nonparametric test. 
Table 3

HER2, ER, and PR status of Tumors from 1362 Breast Cancer Patients According to Race, NCI-SEER Connecticut Tumor Registry, 2000-2003

\begin{tabular}{|c|c|c|c|}
\hline Tumor Status & White ( $\mathrm{n}=719$ ) & Black $(n=643)$ & Pearson $\chi^{2} P$ Value \\
\hline \multicolumn{4}{|l|}{ Triple Subtype } \\
\hline $\mathrm{ER}^{-} \mathrm{PR}^{-} \mathrm{HER} 2^{-}$ & $47(11.2 \%)$ & $128(30.8 \%)$ & $<.001$ \\
\hline $\mathrm{ER}^{-} \mathrm{PR}^{-} \mathrm{HER} 2^{+}$ & $20(4.8 \%)$ & $38(9.2 \%)$ & \\
\hline ER/PR ${ }^{+}$HER2 ${ }^{-}$ & $301(71.5 \%)$ & $205(49.4 \%)$ & \\
\hline $\mathrm{ER} / \mathrm{PR}^{+} \mathrm{HER} 2^{+}$ & $53(12.6 \%)$ & $44(10.6 \%)$ & \\
\hline Missing & 298 & 228 & \\
\hline \multicolumn{4}{|l|}{ HER2 } \\
\hline Positive & $76(17.1 \%)$ & $90(20.5 \%)$ & .19 \\
\hline Negative & $369(82.9 \%)$ & $350(79.5 \%)$ & \\
\hline Missing & 274 & 203 & \\
\hline \multicolumn{4}{|l|}{ ER } \\
\hline Positive & $483(82.4 \%)$ & $318(60.3 \%)$ & $<.001$ \\
\hline Negative & $103(17.6 \%)$ & $209(39.7 \%)$ & \\
\hline Missing & 133 & 116 & \\
\hline \multicolumn{4}{|l|}{ PR } \\
\hline Positive & $407(70.8 \%)$ & $275(53.7 \%)$ & $<.001$ \\
\hline Negative & $168(29.2 \%)$ & $247(47.3 \%)$ & \\
\hline Missing & 144 & 121 & \\
\hline
\end{tabular}

Abbreviations: $\mathrm{ER}=$ estrogen receptor; $\mathrm{HER}=$ human epidermal growth factor receptor; $\mathrm{PR}=$ progesterone receptor. 
Table 4

Age-Adjusted and Multivariate Odds Ratio (OR) for Invasive Triple-negative ${ }^{a}$ Breast Cancer, NCI-SEER Connecticut Tumor Registry, 2000-2003

\begin{tabular}{|c|c|c|c|}
\hline Variable & $\begin{array}{l}\text { Age-Adjusted OR }(95 \% \\
\text { CI })(n=836)\end{array}$ & $\begin{array}{l}\text { Multivariate Model } 1^{b} \text { OR } \\
(95 \% \mathrm{CI})(\mathrm{n}=823)\end{array}$ & $\begin{array}{c}\text { Multivariate Model }{ }^{b} \text { OR }(95 \% \\
\text { CI })(n=789)\end{array}$ \\
\hline \multicolumn{4}{|l|}{ Race } \\
\hline White & 1.00 & 1.00 & 1.00 \\
\hline Black & $3.37(2.33-4.89)$ & $2.93(1.88-4.57)$ & $2.95(1.87-4.66)$ \\
\hline Tumor Size (cm) & - & $1.17(1.02-1.33)$ & $1.16(1.01-1.33)$ \\
\hline Axillary Lymph Nodes (no. positive) & - & $1.00(0.95-1.06)$ & $1.02(0.95-1.08)$ \\
\hline \multicolumn{4}{|l|}{ Tumor Grade } \\
\hline $\mathrm{I} / \mathrm{II}$ & - & 1.00 & 1.00 \\
\hline $\mathrm{III} / \mathrm{IV}$ & & $6.74(4.04-11.27)$ & $6.83(3.99-11.72)$ \\
\hline \multicolumn{4}{|l|}{ Histologic Subtype } \\
\hline Ductal & - & & 1.0 \\
\hline Lobular & & - & $0.25(0.07-0.89)$ \\
\hline Mixed ductal and lobular & & & $0.23(0.10-0.58)$ \\
\hline Medullary & & & $3.37(0.94-12.10)^{c}$ \\
\hline Other or unclassified & & & $1.97(0.78-4.97)$ \\
\hline
\end{tabular}

${ }^{a}$ Compared with all other triple subtypes combined.

${ }^{b}$ All variables (and age) simultaneously assessed in models.

${ }^{c} P=.06$. 


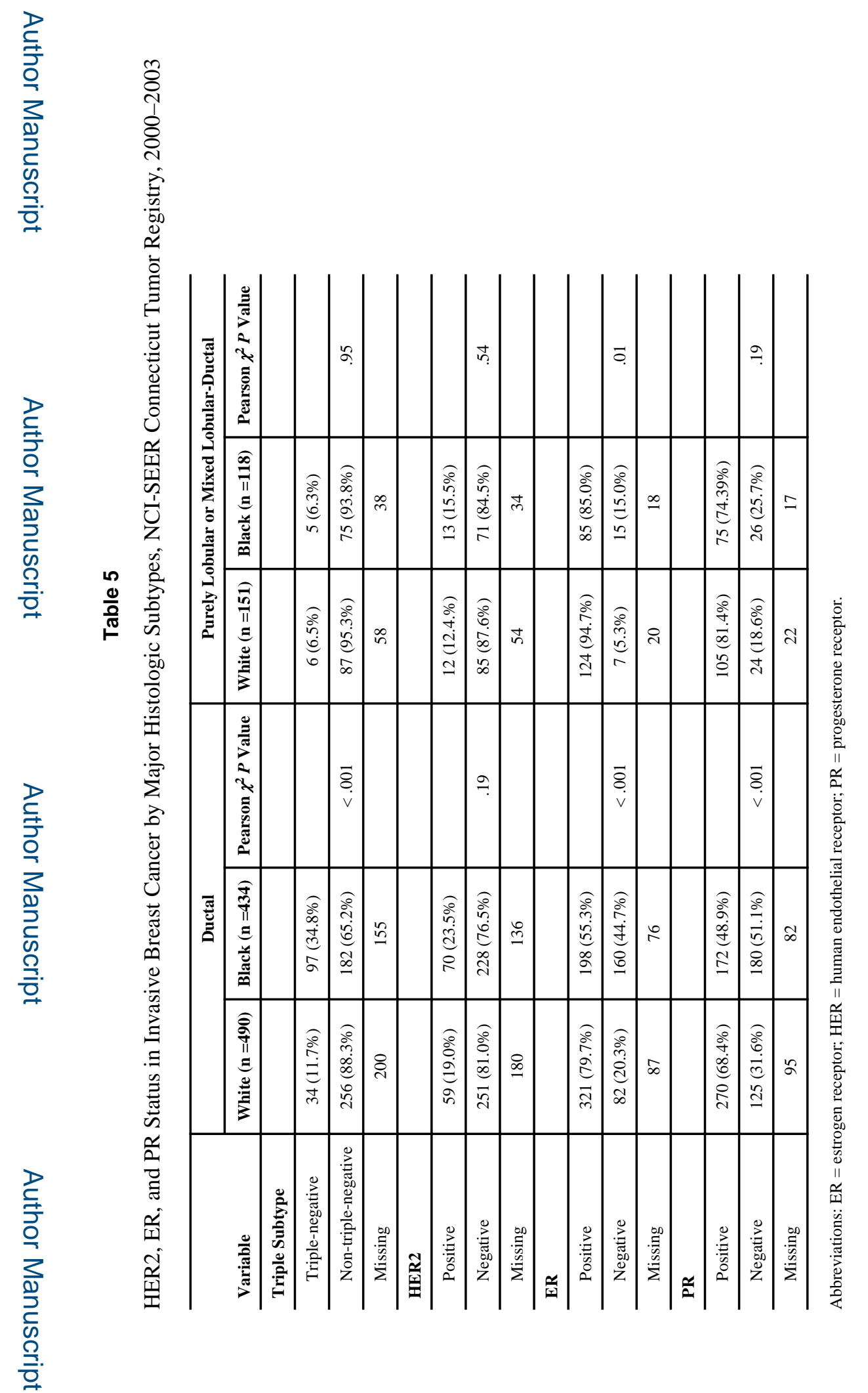

Clin Breast Cancer. Author manuscript; available in PMC 2015 June 08. 


\section{Table 6}

Age-Adjusted and Multivariate Relative Risk (RR) of All-Cause Death in Relation to Triple-Negative Breast Cancer and Race Derived from Cox Proportional Hazards Survival Analyses, ${ }^{a}$ NCI-SEER Connecticut Tumor Registry, 2000-2003

\begin{tabular}{|c|c|c|c|c|c|}
\hline \multicolumn{6}{|c|}{ A: LOCAL STAGE AT DIAGNOSIS } \\
\hline & \multicolumn{2}{|c|}{ Age-Adjusted $^{b}$ RR (95\% CI) } & \multicolumn{2}{|r|}{$\begin{array}{l}\text { Multivariate Model } 1^{c} \operatorname{RR}(95 \% \\
\text { CI) }(\mathrm{n}=420)\end{array}$} & $\underset{(\mathrm{n}=\mathbf{4 2 0})}{\text { Multivariate }} \underset{\text { Model } 2^{c} \text { RR }(95 \% \text { CI) }}{ }$ \\
\hline \multicolumn{6}{|l|}{ Race } \\
\hline White & & 1.00 & & 1.00 & 1.00 \\
\hline Black & & $1.41(1.03-1.93)$ & & $1.03(0.60-1.77)$ & $1.05(0.60-1.81)$ \\
\hline \multicolumn{6}{|l|}{ Triple Subtype } \\
\hline Non-triple-negative & & 1.00 & & 1.00 & 1.00 \\
\hline Triple-negative & & $2.79(1.769-4.34)$ & & $2.67(1.43-4.97)$ & $2.74(1.47-5.15)$ \\
\hline Tumor Size (cm) & & - & & $1.02(1.01-1.04)$ & $1.02(1.01-1.04)$ \\
\hline \multicolumn{6}{|l|}{ Tumor Grade } \\
\hline $\mathrm{I} / \mathrm{II}$ & & - & & 1.00 & 1.00 \\
\hline III/IV & & & & $1.15(0.65-2.05)$ & $1.09(0.61-1.94)$ \\
\hline \multicolumn{6}{|l|}{ Histologic Subtype } \\
\hline Ductal & & - & & & 1.00 \\
\hline Lobular & & & & - & $1.49(0.52-4.25)$ \\
\hline Mixed ductal and lobular & & & & & $0.89(0.38-2.12)$ \\
\hline Medullary & & & & & $1.13(0.27-4.76)$ \\
\hline Other or unclassified & & & & & $0.56(0.13-2.37)$ \\
\hline \multicolumn{6}{|c|}{ B: REGIONAL STAGE AT DIAGNOSIS } \\
\hline & & $\underset{\text { CI) }}{\text { Age-Adjusted }}{ }^{b}$ RR (95 & & $\begin{array}{l}\text { Multivariate Model } 1^{c} \mathrm{RR} \\
\quad(95 \% \mathrm{CI})(\mathrm{n}=\mathbf{2 4 2})\end{array}$ & $\begin{array}{l}\text { Multivariate Model } 2^{c} \text { RR (95\% } \\
\text { CI) }(\mathrm{n}=242)\end{array}$ \\
\hline \multicolumn{6}{|l|}{ Race } \\
\hline White & & 1.00 & & 1.00 & 1.00 \\
\hline Black & & $2.19(1.51-3.17)$ & & $2.79(1.54-5.10)$ & $2.71(1.48-4.97)$ \\
\hline \multicolumn{6}{|l|}{ Triple Subtype } \\
\hline Non-triple-negative & & 1.00 & & 1.00 & 1.00 \\
\hline Triple-negative & & $3.03(1.93-4.75)$ & & $2.15(1.26-3.75)$ & $2.13(1.20-3.75)$ \\
\hline Tumor Size (cm) & & - & & $1.01(0.99-1.02)$ & $1.01(0.99-1.02)$ \\
\hline Positive Axillary Nodes (nun & nber) & - & & $1.05(1.02-1.09)$ & $1.06(1.02-1.09)$ \\
\hline \multicolumn{6}{|l|}{ Tumor Grade } \\
\hline $\mathrm{I} / \mathrm{II}$ & & - & & 1.00 & 1.00 \\
\hline III/IV & & & & $2.27(1.16-4.42)$ & $2.43(1.23-4.77)$ \\
\hline \multicolumn{6}{|l|}{ Histologic Subtype } \\
\hline Ductal & & - & & & 1.00 \\
\hline Lobular & & & & - & $1.49(0.52-4.25)$ \\
\hline
\end{tabular}




\begin{tabular}{|c|c|c|c|}
\hline \multicolumn{4}{|c|}{ B: REGIONAL STAGE AT DIAGNOSIS } \\
\hline & $\underset{\text { CI) }}{\text { Age-Adjusted }}{ }^{b}$ RR (95\% & $\begin{array}{l}\text { Multivariate Model } 1^{c} \mathrm{RR} \\
\quad(95 \% \mathrm{CI})(\mathrm{n}=242)\end{array}$ & $\begin{array}{l}\text { Multivariate Model } 2^{c} \text { RR (95\% } \\
\text { CI) }(\mathrm{n}=242)\end{array}$ \\
\hline Mixed ductal and lobular & & & $0.49(0.17-1.39)$ \\
\hline Medullary & & & $0.31(0.04-4.76)$ \\
\hline Other or unclassified & & & $1.63(0.49-5.34)$ \\
\hline
\end{tabular}

Abbreviations: $\mathrm{CI}=$ confidence interval; $\mathrm{RR}=$ relative risk.

${ }^{a}$ Excluded patents with distant disease at diagnosis or who survived less than 1 month.

${ }^{b}$ Age-adjusted RRs calculated separately for race $(\mathrm{n}=672)$ and triple subtype $(\mathrm{n}=438)$.

${ }^{c}$ All variables in model simultaneously controlled. 